\title{
Community Composition and Function of Bacteria in Activated Sludge of Municipal Wastewater Treatment Plants
}

\author{
Ning Xie ${ }^{1}$, Liping Zhong ${ }^{1}$, Liao Ouyang ${ }^{1}$, Wang $\mathrm{Xu}^{2}{ }^{2}$, Qinghuai Zeng ${ }^{2}$, Keju Wang ${ }^{1}$, Madiha Zaynab ${ }^{1}$, \\ Huirong Chen ${ }^{1}$, Fangfang $\mathrm{Xu}^{1, *}$ (i) and Shuangfei $\mathrm{Li}^{1, *}$ \\ 1 Shenzhen Key Laboratory of Marine Bioresource \& Eco-Environmental Sciences, College of Life Sciences and \\ Oceanography, Shenzhen University, Shenzhen 518071, China; shainin@msn.cn (N.X.); \\ zhongliping_12@163.com (L.Z.); ouyangliao@hotmail.com (L.O.); wkj227177@163.com (K.W.); \\ madiha.zaynab14@gmail.com (M.Z.); chenhr@szu.edu.cn (H.C.) \\ 2 Shenzhen Environmental Monitoring Center, Shenzhen 518049, China; xuwang820126@163.com (W.X.); \\ zengqinghuai@126.com (Q.Z.) \\ * Correspondence: ff.xu@szu.edu.cn (F.X.); szu_sfli@163.com (S.L.)
}

check for updates

Citation: Xie, N.; Zhong, L.; Ouyang, L.; Xu, W.; Zeng, Q.; Wang, K.; Zaynab, M.; Chen, H.; Xu, F.; Li, S. Community Composition and Function of Bacteria in Activated Sludge of Municipal Wastewater Treatment Plants. Water 2021, 13, 852 https://doi.org/10.3390/w13060852

Academic Editor: Françoise S. Lucas, Pierre Servais and Leslie Ogorzaly

Received: 19 February 2021

Accepted: 17 March 2021

Published: 20 March 2021

Publisher's Note: MDPI stays neutral with regard to jurisdictional claims in published maps and institutional affiliations.

Copyright: (c) 2021 by the authors. Licensee MDPI, Basel, Switzerland. This article is an open access article distributed under the terms and conditions of the Creative Commons Attribution (CC BY) license (https:// creativecommons.org/licenses/by/ $4.0 /)$.

\begin{abstract}
Municipal wastewater treatment plants (WWTPs) use functional microorganisms in activated sludge (AS) to reduce the environmental threat posed by wastewater. In this study, Illumina NovaSeq sequencing of $16 \mathrm{~S}$ rRNA genes was performed to explore the microbial communities of AS at different stages of the two WWTP projects in Shenzhen, China. Results showed that Proteobacteria, Bacteroidetes, Acidobacteria, Firmicutes, and Nitrospirae were the dominant phyla in all the samples, with Proteobacteria being the most abundant and reaching a maximum proportion of $59.63 \%$. There was no significant difference in biodiversity between the two water plants, but Stage 1 and Stage 2 were significantly different. The Mantel test indicated that nitrate, total nitrogen (TN), chemical oxygen demand (COD), and nutrients were essential factors affecting the bacterial community structure. FAPROTAX analysis emphasized that the leading functional gene families include nitrification, aerobic nitrite oxidation, human pathogens, and phototrophy. This study reveals changes in the community structure of AS in different treatment units of Banxuegang WWTP, which can help engineers to optimize the wastewater treatment process.
\end{abstract}

Keywords: wastewater treatment plant; activated sludge; community structure; Illumina NovaSeq sequencing; nutrients

\section{Introduction}

With rapid socio-economic development, the total amount of sewage emissions in China is increasing [1]. Domestic sewage and industrial effluents, which contain abundant nutrients and toxic compounds, can degrade environmental quality in multiple ways [2-4]. Thus, proper treatment of sewage is required before it can be discharged. Wastewater treatment plants (WWTPs) are infrastructures in which sewage is treated to meet discharge standards. Activated sludge (AS) is commonly used in WWTPs to treat various types of sewage [5]. AS is a unique artificial ecosystem with a high microbial diversity [6] and a high concentration of biomass (typically 2-10 mg/L) [7,8]. This ecosystem mainly consists of eukaryotes, bacteria, archaea, and viruses, with bacteria dominating the system. Highly diverse bacterial communities have superior sewage treatment performance $[9,10]$.

Over the past few decades, efforts have been devoted to isolating functional microorganisms in AS, such as nitrogen and phosphorus removing bacteria [11-13], strains leading to sludge flocculation [14], and harmful strains that cause sludge swelling and foaming [7,15]. Despite this, studies of microbial composition and microbial interactions at different stages of the long-term running WWTPs are still limited. Exploring the microbial community process can help to elucidate the hidden biological mechanisms. 
Traditional methods to explore microbial communities mainly consist of molecular biology-derived techniques such as real-time quantitative PCR (RT-qPCR) and denaturing gradient gel electrophoresis (DGGE) [16]. Illumina sequencing technology has become a popular method in community structure determination because of its large sample throughput $[17,18]$. Cai et al. [19] used Illumina NovaSeq to explore bacterial assemblages in two different activated sludge systems. This method was also used to examine changes in the sludge community in the simultaneous nitrification, denitrification, and phosphorus removal (SNDPR) system at low pressure [20]. Illumina sequencing of bacterial 16S rRNA provides DNA diversity of the bacterial cells, although it cannot differ living bacteria from dead bacteria.

In this study, to understand further the community structure of microorganisms during different stages of WWTPs, 14 sludge samples were obtained from two WWTPs in Banxuegang (Shenzhen, China). Illumina NovaSeq high-throughput sequencing was used to analyze the microbial community compositions. The main objectives were as follows: first, to identify the dominant microorganisms in different stages of WWTPs sewage; second, to compare the microbial community structure and dominant bacteria in the various stages; third, to explore the relationship between the microbial community structure and environmental factors; and fourth, to determine the potential functions of microorganisms. Our findings will contribute to our understanding of AS functioning in WWTPs.

\section{Materials and Methods}

\subsection{Sample Collection}

Banxuegang WWTPs are located in Buji Town in Shenzhen City, China, with an average daily wastewater treatment capacity of $35,200,000 \mathrm{~m}^{3} /$ day. The WWTPs consist of two projects, WWTP A and WWTP B, which became operational in 2004 and 2019, respectively. WWTP A adopts an improved anaerobic-anoxic-oxic $\left(\mathrm{A}^{2} / \mathrm{O}\right)$ treatment process, WWTP $B$ adopts an improved $A^{2} / O$ treatment process with a membrane bioreactor (MBR). In this study, 14 representative samples were collected from the two projects (Figure 1). Field surveys and sample collection were conducted on 5 June 2020. For WWTP A, the chosen sample sites were the primary clarifier (BXAS 1), biological tank (BXAS 2-4), sludge reflux (BXAS 5), and secondary clarifier (BXAS 6). For WWTP B, chosen sample sites were the primary clarifier (BXBS 1), biological tanks (north and south, BXBS 2-4), and sludge storage tank (BXBS 5). Three different samples were collected at each sampling site for a total of $900 \mathrm{~mL}$ in pre-rinsed sterile plastic bottles, and a Plexiglas sampler was used for sample collection (2.5 L, GWS-117, Wuhan Peterson Technology Co., Ltd., Wuhan, China). Temperature, $\mathrm{pH}$, and concentration of dissolved oxygen (DO) were measured immediately with an Orion Star A 329 multiparameter probe (Thermo Scientific, Waltham, MA, USA) at the site. The samples were transported back to the laboratory on ice (within $3 \mathrm{~h}$ ) and were directly centrifuged at $8000 \mathrm{rpm}$ for $10 \mathrm{~min}$. The water sample was filtered using a $0.45 \mu \mathrm{M}$ filter membrane (Merck KGaA, Darmstadt, Germany) to determine $\mathrm{NH}_{4}{ }^{+}-\mathrm{N}, \mathrm{NO}_{2}{ }^{-}-\mathrm{N}$, $\mathrm{NO}_{3}{ }^{-}-\mathrm{N}$, total nitrogen (TN), total phosphorus (TP), and chemical oxygen demand (COD). The centrifuged sludge samples were stored at $-80^{\circ} \mathrm{C}$.

\subsection{Physical and Chemical Analysis}

$\mathrm{NH}_{4}{ }^{+}-\mathrm{N}, \mathrm{NO}_{2}{ }^{-}-\mathrm{N}, \mathrm{NO}_{3}{ }^{-}-\mathrm{N}, \mathrm{TN}, \mathrm{TP}, \mathrm{COD}$, and sludge volume index (SVI) of samples were measured according to the following standard methods [21]: salicylic acid spectrophotometric method for the determination of $\mathrm{NH}_{4}{ }^{+}$; UV spectrophotometric method for the determination of nitrate; the spectrophotometric method for the determination of nitrite; alkaline potassium persulfate elimination UV spectrophotometric method for the determination of total nitrogen (TN); ammonium molybdate spectrophotometric method for the determination of total phosphorus (TP); and SVI [22] was determined by transferring the sludge to a $1 \mathrm{~L}$ graduated cylinder, and allowing the sludge to settle undisturbed for $30 \mathrm{~min}$. 


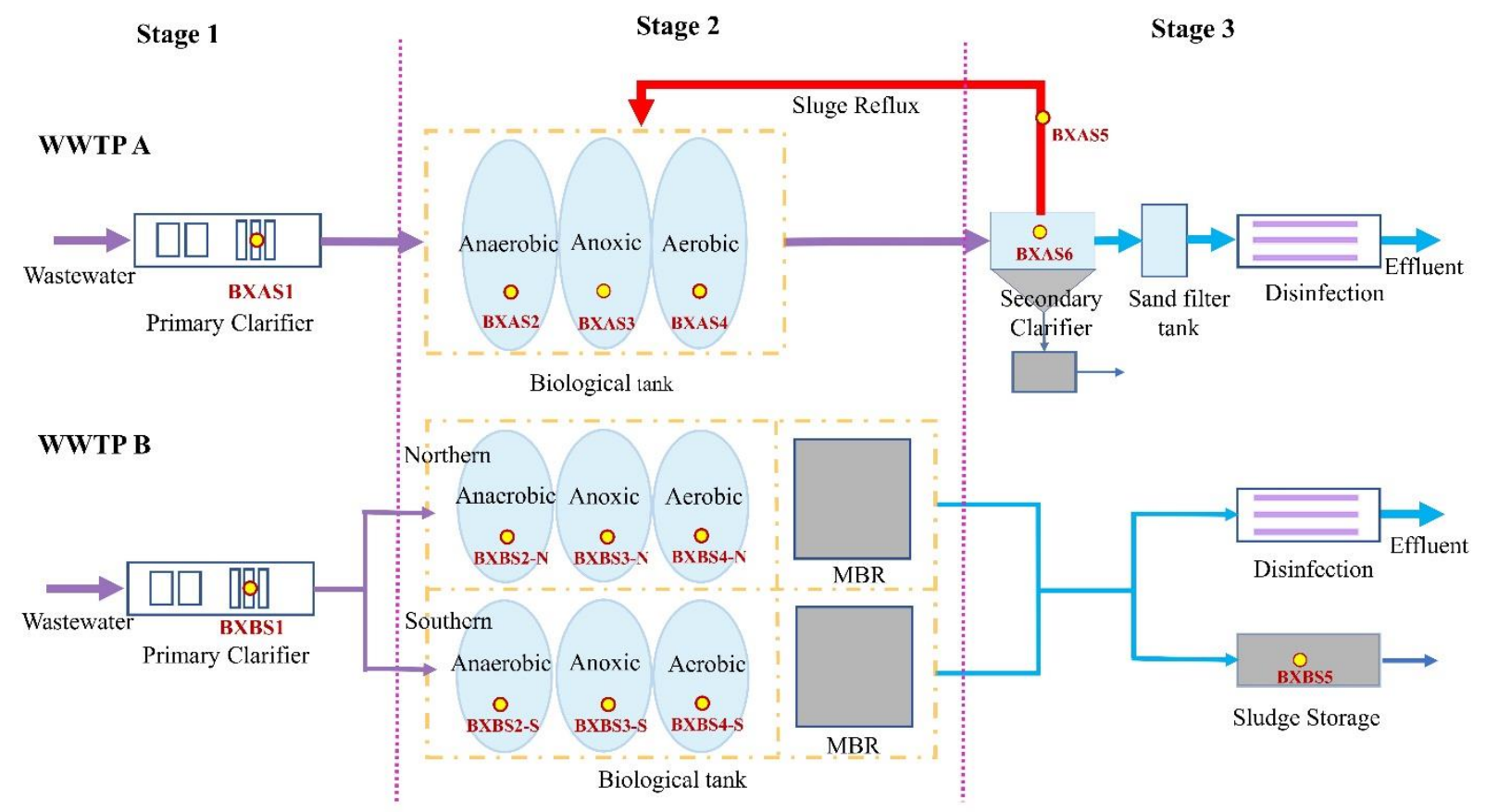

Figure 1. Schematic drawing of the two projects. Sampling points are indicated by yellow dots.

\subsection{DNA Extraction and Illumina NovaSeq Sequencing}

All samples were sent to "Health Time Gene" (Shenzhen, China) for DNA extraction, PCR amplification, and sequencing. DNA was extracted from the samples using an EZNA DNA kit (OMEGA Bio-Tek, Norcross, GA, USA). Universal primers 341 F (CCTAYGGGRBGCASCAG) and 806 R (GGACTACNNGGGTATCTAAT) were used to amplify the bacterial $16 \mathrm{~S}$ rRNA V3-V4 hypervariable region. The PCR system conditions were as follows: denaturation at $98^{\circ} \mathrm{C}$ for $1 \mathrm{~min}, 30$ cycles of $98^{\circ} \mathrm{C}$ for $10 \mathrm{~s}, 50^{\circ} \mathrm{C}$ for $30 \mathrm{~s}, 72^{\circ} \mathrm{C}$ for $30 \mathrm{~s}$, and a final extension at $72{ }^{\circ} \mathrm{C}$ for $5 \mathrm{~min}$. PCR products were examined using $2 \%$ gel electrophoresis and prominent bands were obtained for gel recovery. The bands were then purified using the GeneJET Gel DNA Gel Extraction Kit (Thermo Fisher Scientific, Waltham, MA, USA) to obtain purified amplicons. Lastly, sequencing was performed using the Illumina NovaSeq PE 2500 platform (Illumina, San Diego, CA, USA).

\subsection{Data Processing and Analysis}

Low-quality raw sequences were filtered using the QIIME (v 1.17) package [23]. Highquality, paired read segments were merged using FLASH [24]. This was carried out as follows: (1) After setting $30 \mathrm{bp}$ as the window length, fragments with an average fragment mass below $20 \mathrm{bp}$ were excised; low-quality fragments and N-containing fragments were removed; (2) based on the overlapping relationship between PE read segments, the segments with overlap region lengths greater than $10 \mathrm{bp}$ and mismatch ratios below 0.2 were merged; (3) single columns were removed using UCHIME (v 4.2.40) [25]. High-quality $16 \mathrm{~S}$ rRNA sequences generated from 14 samples were classified using VSEARCH (v 2.4.4) software [26] with 97\% similarity for operational taxonomic unit (OTU) classification [27]. The RDP(Ribosomal Database Project) classifier (version 2.2) Bayesian algorithm was used to classify OTU representative sequences with a $97 \%$ similarity level. Then, compared with the Silva ( $v$ 132) database, the community composition of each sample was counted.

\subsection{Community Structure Analysis}

OTUs with $97 \%$ similarity were selected for subsequent analysis. Species accumulation curves were used to estimate the validity of the sample size. The alpha diversity indices, such as Chao 1 values and Shannon index, were analyzed using the "vegan" package in R. 
Based on the taxonomic analysis, a bar chart of species composition community analysis (community composition of phyla, families, and genera) was obtained. Principal coordinate analysis ( $\mathrm{PCoA}$ ) plots for comparative analysis of samples were generated using the $\mathrm{R}$ package $[28,29]$. Permutational multivariate analysis of variance (PERMANOVA) was used to analyze the possible relationships between environmental factors and microbial communities or species. Multivariate analysis of similarities (ANOSIM) [29] was used to assess the similarity of microbial community structure. Functional annotation of prokaryotic taxa (FAPROTAX) is based on the current prokaryotic function annotation library of cultivable bacteria, which is more suitable for functional annotation and prediction of environmental samples. Therefore, FAPROTAX was used to obtain different potential functions of microorganisms.

\section{Results}

\subsection{Sample Characteristics}

The characteristics of the samples are summarized in Table 1. $\mathrm{pH}$ values ranged from 6.18 to 7.44 , with higher $\mathrm{pH}$ values at BXAS 1 and BXBS 1. The DO ranged from $0 \mathrm{mg} / \mathrm{L}$ at BXBS2. $\mathrm{N}$ to $3.28 \mathrm{mg} / \mathrm{L}$ at BXBS 1 . The temperature range was 28.4 to $31.7^{\circ} \mathrm{C}$, with the highest temperatures observed in the anaerobic tank in the WWTP B (BXBS2.S). The TN in WWTP A decreased from $26.78 \mathrm{mg} / \mathrm{L}$ to $5.81 \mathrm{mg} / \mathrm{L}$, with a removal rate of $66.8 \%$; TP concentration decreased from 2.03 to $0.76 \mathrm{mg} / \mathrm{L}$, with a removal rate of $62.6 \%$. For WWTP B, TN and TP concentrations decreased from 25.21 to $1.74 \mathrm{mg} / \mathrm{L}$ and 2.22 to $0.95 \mathrm{mg} / \mathrm{L}$, with removal rates of $76.24 \%$ and $50.45 \%$, respectively. The two WWTPs showed high TN and TP removal rates, and the qualities of the effluents met the primary class B standard of "Discharge Standard for Pollutants from Urban Wastewater Treatment Plants" (GB18918-2002).

Table 1. Physicochemical parameters of wastewater treatment plants (WWTPs) under study.

\begin{tabular}{|c|c|c|c|c|c|c|c|c|c|c|c|c|c|}
\hline \multirow{2}{*}{$\begin{array}{l}\text { Grouping } \\
\text { Program } 1\end{array}$} & \multirow{2}{*}{$\begin{array}{l}\text { Grouping } \\
\text { Program } 2\end{array}$} & \multirow[t]{2}{*}{ Sample } & \multirow{2}{*}{$\frac{\text { Temperature }}{{ }^{\circ} \mathrm{C}}$} & \multicolumn{2}{|c|}{ pH Conductivity } & \multirow[t]{2}{*}{ DO } & \multirow[t]{2}{*}{ SVI } & \multicolumn{2}{|c|}{ Ammonium Nitrite } & \multicolumn{2}{|c|}{ Nitrate TN } & \multirow[t]{2}{*}{ TP } & \multirow[t]{2}{*}{ COD } \\
\hline & & & & & & & & $\mathrm{mg} / \mathrm{L}$ & & & & & \\
\hline \multirow{6}{*}{$\mathrm{A}$} & Stage 1 & BXAS1 & 28.40 & 7.44 & 203.90 & 3.18 & 12.50 & 25.26 & 0.08 & 0.27 & 26.78 & 2.03 & 53.47 \\
\hline & \multirow{3}{*}{ Stage 2} & BXAS2 & 29.00 & 7.07 & 540.40 & 0.63 & 35.36 & 16.83 & 0.08 & 1.30 & 17.84 & 1.83 & 37.47 \\
\hline & & BXAS3 & 29.50 & 6.81 & 490.70 & 0.72 & 39.60 & 7.34 & 0.17 & 3.26 & 12.74 & 1.30 & 44.13 \\
\hline & & BXAS4 & 29.10 & 6.57 & 468.60 & 2.13 & 40.00 & 3.54 & 0.08 & 3.79 & 8.48 & 1.03 & 10.80 \\
\hline & \multirow{2}{*}{ Stage 3} & BXAS5 & 30.10 & 6.51 & 449.70 & 1.00 & 39.34 & 1.64 & 0.17 & 2.94 & 5.81 & 1.33 & 42.80 \\
\hline & & BXAS6 & 28.80 & 6.18 & 461.80 & 1.03 & 33.33 & 0.80 & 0.04 & 6.00 & 8.89 & 0.76 & 22.80 \\
\hline \multirow{8}{*}{ B } & Stage 1 & BXBS1 & 28.50 & 7.30 & 623.20 & 3.28 & 5.00 & 23.79 & 0.04 & 0.23 & 25.21 & 2.22 & 62.80 \\
\hline & \multirow{6}{*}{ Stage 2} & BXBS2.S & 31.70 & 6.82 & 547.30 & 0.16 & 33.00 & 6.92 & 0.12 & 0.74 & 9.07 & 1.29 & 32.13 \\
\hline & & BXBS3.S & 29.43 & 6.72 & 525.10 & 0.10 & 24.25 & 2.07 & 0.58 & 1.00 & 3.30 & 0.49 & 5.47 \\
\hline & & BXBS4.S & 29.96 & 6.68 & 522.80 & 1.80 & 29.47 & 0.00 & 0.33 & 1.84 & 1.74 & 0.49 & 28.13 \\
\hline & & BXBS2.N & 31.60 & 6.89 & 550.00 & 0.00 & 25.00 & 7.76 & 0.00 & 0.81 & 10.01 & 1.76 & 18.80 \\
\hline & & BXBS3.N & 29.80 & 6.79 & 520.90 & 0.02 & 31.25 & 1.43 & 0.17 & 1.18 & 4.74 & 1.22 & 14.80 \\
\hline & & BXBS4.N & 29.54 & 6.76 & 515.90 & 2.28 & 30.48 & 3.12 & 0.00 & 1.41 & 3.15 & 0.95 & 12.13 \\
\hline & Stage 3 & BXBS5 & 29.00 & 6.85 & 524.50 & 2.04 & 28.00 & 4.18 & 0.08 & 0.87 & 5.90 & 1.08 & 22.80 \\
\hline
\end{tabular}

DO, dissolved oxygen; TP, total phosphorus; TN, total nitrogen; COD, chemical oxygen demand; SVI, sludge volume index.

\subsection{Richness and Diversity of Bacterial Communities}

A total of 959,657 valid bacterial $16 \mathrm{~S}$ rRNA sequences were obtained from 14 samples, and at least 54,034 useful sequences were obtained per sample with an average length of $418 \mathrm{bp}$. The total number of OTUs at $97 \%$ similarity level was 27,950 , with the lowest observed at sample BXAS 5 (1464), and the highest was at BXBS 5 (2689) (Table 2). The species accumulation curves of the samples tended to be flat, indicating an adequate sample size. 
Table 2. Alpha diversity of samples.

\begin{tabular}{cccccc}
\hline & Shannon & Chao 1 & $\begin{array}{c}\text { Observed } \\
\text { Species }\end{array}$ & $\begin{array}{c}\text { PD Whole } \\
\text { Tree }\end{array}$ & $\begin{array}{c}\text { OTU } \\
\text { Number }\end{array}$ \\
\hline BXAS1 & 7.8696 & 1782.69 & 1746 & 100.9319 & 1965 \\
BXAS2 & 8.4169 & 2155.26 & 1943 & 114.8954 & 2227 \\
BXAS3 & 8.8675 & 2264.85 & 2025 & 117.9512 & 2281 \\
BXAS4 & 8.6528 & 2145.23 & 1877 & 111.7669 & 2143 \\
BXAS5 & 7.5448 & 1600.30 & 1253 & 80.8964 & 1464 \\
BXAS6 & 7.6178 & 1591.58 & 1402 & 77.656 & 1574 \\
BXBS1 & 7.1054 & 1872.23 & 1640 & 99.3052 & 1926 \\
BXBS2.S & 7.5643 & 2051.50 & 1496 & 98.4937 & 1758 \\
BXBS3.S & 8.262 & 1911.95 & 1591 & 103.3599 & 1751 \\
BXBS4.S & 8.8196 & 2274.63 & 2045 & 118.6655 & 2360 \\
BXBS2.N & 8.7594 & 2130.87 & 1893 & 117.5945 & 2126 \\
BXBS3.N & 7.4933 & 1640.02 & 1245 & 86.3666 & 1469 \\
BXBS4.N & 8.7389 & 2192.48 & 1944 & 122.5322 & 2217 \\
BXBS5 & 9.0738 & 2818.80 & 2399 & 122.2691 & 2689 \\
\hline
\end{tabular}

The Chao 1 index ranged from 1591 to 2818, with BXAS 6 being the lowest and BXBS 5 the highest. The observed species index ranged from 1245 to 2399, with BXBS 3.N being the lowest and BXBS 5 the highest. Changes in Chao 1 and observed species indices were consistent with the total number of OTUs. The Shannon index ranged from 7.1 to 9.0, with BXBS 1 being the lowest and BXBS 5 the highest. The phylogenetic diversity (PD whole tree) index ranged from 77.6 to 122.5. The highest Chao, observed species, and Shannon indices were all found at sample BXBS 5 in WWTP B, indicating that BXBS 5 had the highest species richness and diversity. Overall, the richness and diversity of Stage 2 were higher than those of Stage 1 and Stage 3, and there was little difference in WWTP A and WWTP B $(p=0.366)$.

\subsection{Microbial Taxonomy and Community Composition Analysis}

The top five phyla in the 14 samples (Figure 2A) were Proteobacteria, Bacteroidetes, Acidobacteria, Firmicutes, and Nitrospirae, with the highest abundance of Proteobacteria ranging from $24.15-59.63 \%$. The dominant phyla in all 14 samples were relatively homogeneous, but the proportion of each phylum changed at different stages. In WWTP A, Proteobacteria was the most dominant phylum at Stage 1 (BXAS 1), accounting for $59.6 \%$ of the total bacteria, followed by Bacteroidetes, accounting for 21.5\%. At Stage 3 (samples BXAS 5 and BXAS 6), Bacteroidetes was the most dominant phylum ( $38.11 \%$ and $40.77 \%)$, while Proteobacteria accounted for $37.63 \%$ and $32.04 \%$, respectively. At Stage 2, the percentages of Nitrospirae in samples BXAS 2, BXAS 3, and BXAS 4 were $6.9 \%, 4.4 \%$, and $5.8 \%$, respectively, which were higher than those in Stage 1 (BXAS $1(1.8 \%)$ ) and Stage 3 (BXAS $5(0.27 \%)$ and BXAS $6(0.38 \%))$. In WWTP B, from Stage 1 to Stage 3, Bacteroidetes and Firmicutes decreased from $23.15 \%$ and $9.19 \%$ to $12.80 \%$ and $2.71 \%$, respectively. Similarly, in WWTP B, the percentages of Nitrospirae and Chloroflexi were higher in Stage $2(4.70 \%, 3.88 \%)$ than in Stage $1(0.72 \%, 0.72 \%)$ and $3(3.63 \%, 2.21 \%)$. Acidobacteria (Stage2) were more abundant in WWTP B (8.44\%) than in WWTP A (4.24\%).

The top five families of the samples (Figure 2B) were Chitinophagaceae, Campylobacteraceae, Kofleriaceae, Flavobacteriaceae, and NS9.marine. The top four genera (Figure 2C) were Haliangium (0.2-16.9\%), Arcobacter (0.01-13.1\%), Ferruginibacter (0.2-12.3\%), and Cloacibacterium $(0.1-11.7 \%)$. The percentage of genera in the samples varied among sampling sites, indicating that the distribution of genera in the samples was diverse. In WWTP A, Arcobacter and Cloacibacterium were the most dominant genera at Stage 1 (BXAS 1), accounting for $9.82 \%$ and $11.20 \%$, respectively. In Stage 3 (BXAS 5), Ferruginibacter (10.6\%), and Terrimonas $(3.23 \%)$ were dominant. In Stage 2 (samples BXAS 2, BXAS 3, and BXAS 4), Haliangium was the most dominant genera $(16.87 \%, 12.90 \%$, and $11.12 \%$, respectively), followed by Nitrospira $(6.89 \%, 4.38 \%$, and $5.75 \%$, respectively). Similarly, Acidobacteria and Cloacibacterium 
were the most dominant genera at Stage 1 (BXBS 1) in WWTP B, accounting for 13.07\% and $11.68 \%$, respectively. However, in Stage 3 (BXBS 5), Haliangium and Nitrospira were the most dominant genera, accounting for $8.09 \%$ and $3.63 \%$, respectively. Similar to WWTP A, Haliangium and Nitrospira were more predominant in Stage 2.

Temperature and TN are important factors affecting the relative abundance of microbial communities. At the phylum level, temperature had a significant negative correlation $(r=-0.425, p=0.029)$ with Proteobacteria. At the family level, the relative abundance of Flavobacteriaceae was positively correlated with $\mathrm{TN}(r=0.336, p=0.043)$ and negatively correlated with conductivity $(r=-0.503, p=0.042)$. At the genus level, temperature was positively correlated with Ferruginibacter $(r=0.658, p=0.011)$. Cloacibacterium was positively correlated with TN $(r=0.301, p=0.027)$ and negatively correlated with conductivity $(r=-0.481, p=0.04)$.
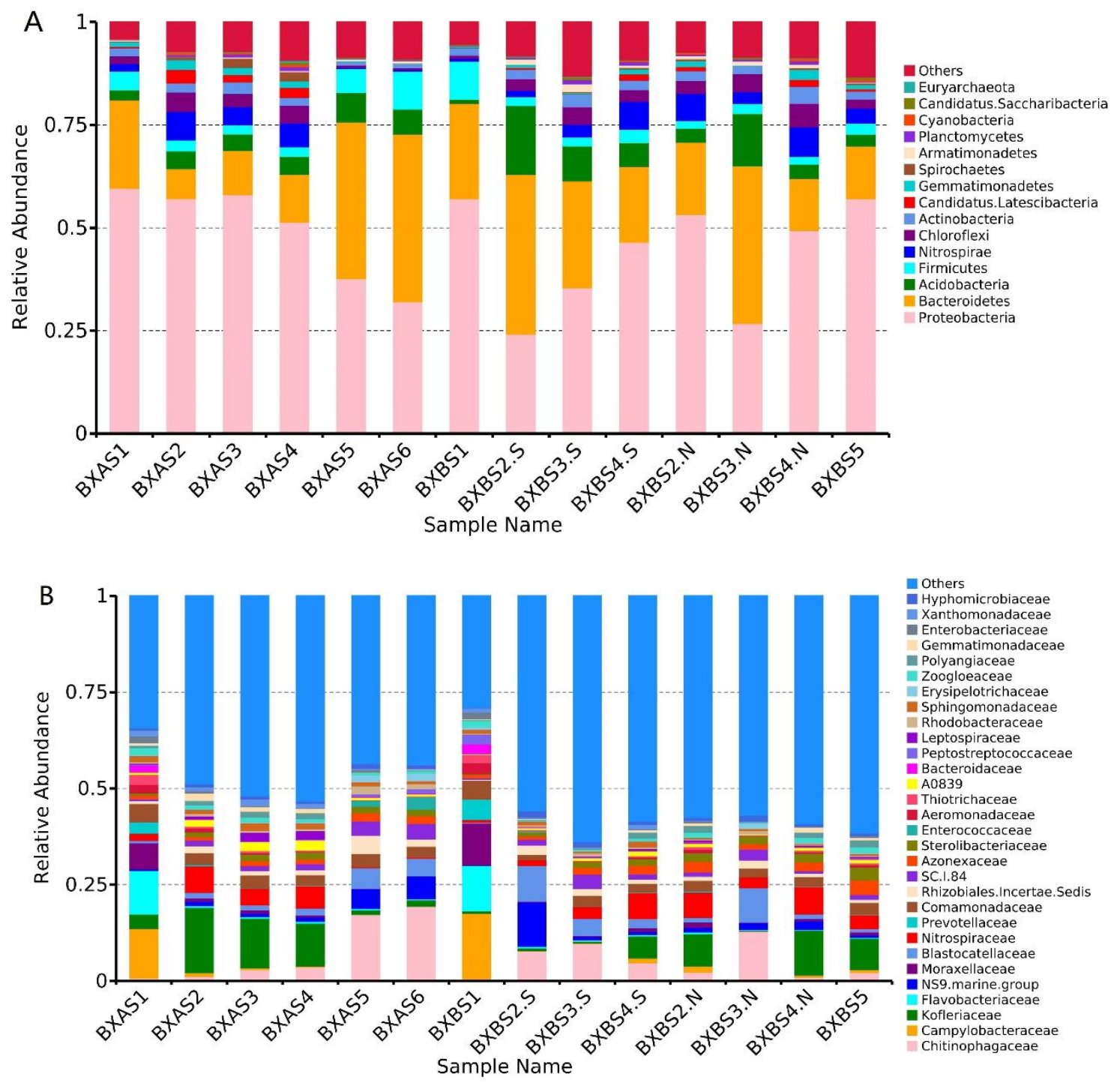

Figure 2. Cont. 


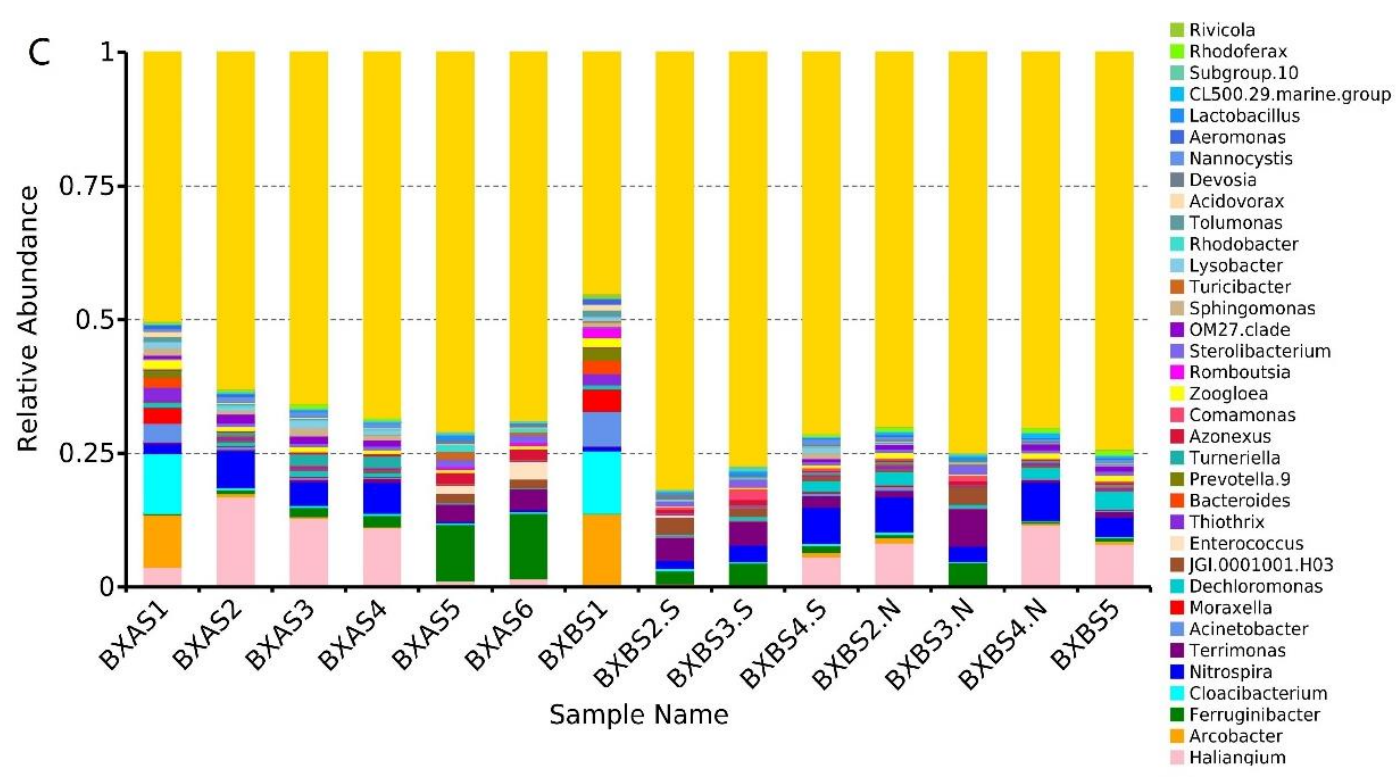

Figure 2. Histogram of the relative abundance of bacterial phyla-(A) top 15 species at the phylum level; (B) top 15 species at the family level; and (C) top 15 species at the genus level.

\subsection{Microbial Community Variation Analysis}

The similarity of the bacterial community compositions of the samples was represented using the PCoA plot, with PC1 representing 39\% (Figure 3). For WWTP A, samples of Stage 2 (BXAS 2, BXAS 3, and BXAS 4) were close to each other, indicating that they have similar microbial community compositions. Samples of Stage 3 (BXAS 5 and BXAS 6) were further away from each other, while BXAS 1 from Stage 1 was further away from both of them, indicating the different community compositions of the three stages. Similar to WWTP A, samples from Stage 1 were far from both Stages 2 and 3 in WWTP B. In WWTP B, samples from biological tanks, BXBS 2.S, BXBS 3.S, and BXBS 3.N were separated from each other (Figure 3), indicating different community compositions in the southern and northern anaerobic tanks. In conclusion, the samples were closer within each group and further apart between groups in Stages 1,2, and 3, indicating that the stages differed in bacterial community compositions.

ANOSIM analysis showed that there were no significant differences in community structure between WWTP A and B (Table 3). There were no significant differences in community structure between Stage 1 and Stage 3, and Stage 2 and Stage 3 (Table 3). However, there were significant differences in community structure between Stage 1 and Stage 2 (Table 3). The results indicated that the community structure of the samples in the biological tanks was significantly different from that in the primary clarifiers.

Table 3. ANOSIM analysis of differences between groups.

\begin{tabular}{ccc}
\hline Group & R-Value & $p$-Value \\
\hline A-B & 0.1696 & 0.082 \\
Stage 1-Stage 3 & 0.8333 & 0.2 \\
Stage 2-Stage 3 & 0.2934 & 0.059 \\
Stage 1-Stage 2 & 0.7718 & 0.02 \\
\hline
\end{tabular}




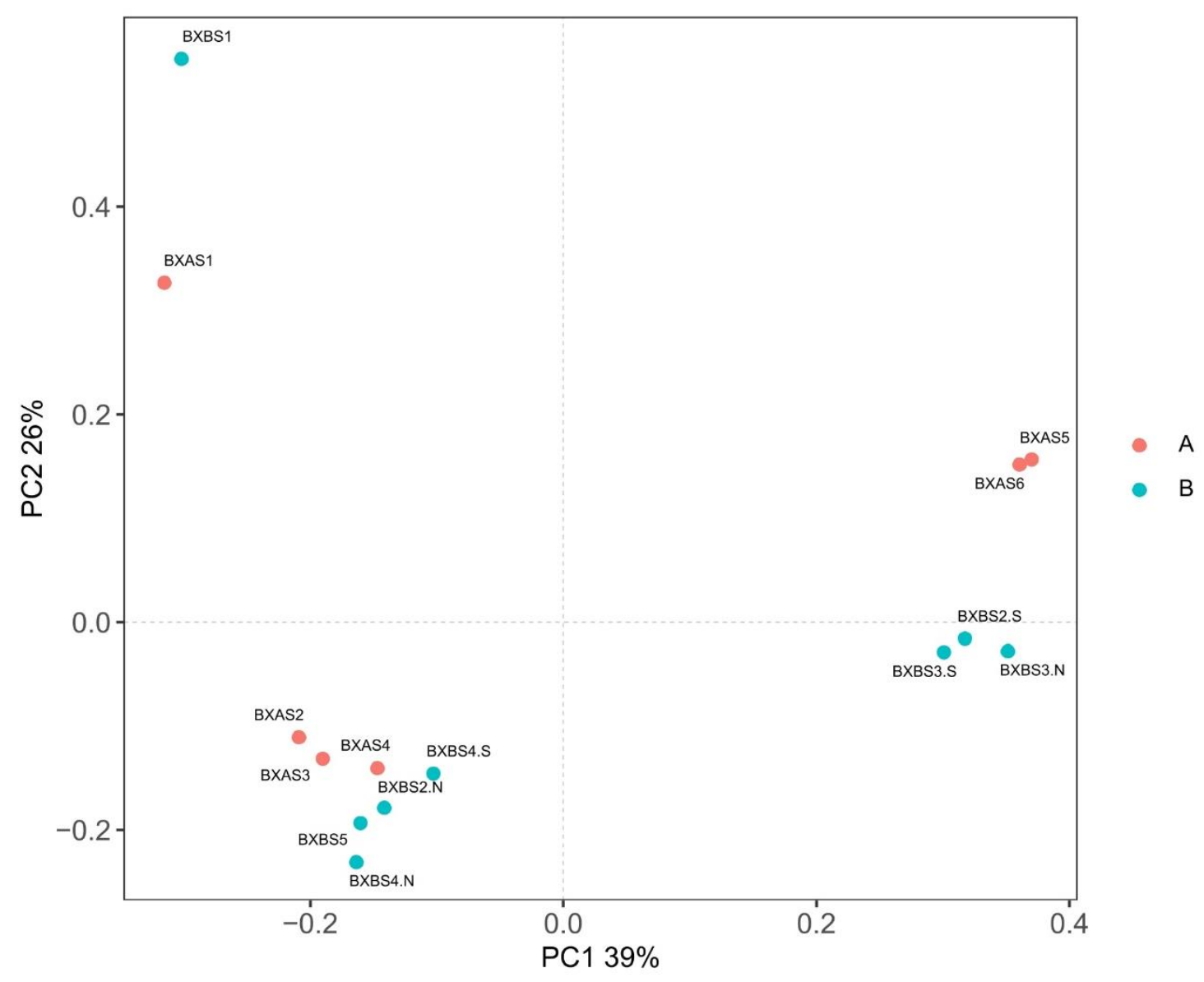

Figure 3. Principal coordinate analysis (PCoA) of samples.

Environmental factors play an important role in the structural composition of microbial communities [30]. The Mantel test was used to analyze the correlation between a single or a group of environmental factors and the whole microbial community. The Mantel test results indicated that nitrate, $\mathrm{TN}, \mathrm{COD}$, and nutrients were the factors that significantly influenced the distribution of microbial communities (Table 4).

Table 4. Results of Mantel test for environmental factors.

\begin{tabular}{ccc}
\hline & $\mathbf{r}^{2}$ & Pr $(>\mathbf{r})$ \\
\hline Temperature & 0.1682 & 0.3668 \\
pH & 0.3870 & 0.0634 \\
Conductivity & 0.0710 & 0.6866 \\
DO & 0.4238 & 0.0559 \\
SVI & 0.0880 & 0.6236 \\
Ammonium & 0.4049 & 0.0554 \\
Nitrite & 0.3004 & 0.1319 \\
Nitrate & 0.4276 & 0.0409 \\
TN & 0.4751 & 0.0294 \\
TP & 0.3490 & 0.0864 \\
COD & 0.4614 & 0.0374 \\
Physicochemical factors & 0.2873 & 0.1098 \\
Nutrients & 0.4500 & 0.0119
\end{tabular}

DO, dissolved oxygen; TP, total phosphorus; TN, total nitrogen; COD, chemical oxygen demand; SVI, sludge volume index. 
Variance partitioning analysis (VPA) results showed that physicochemical factors (including temperature, $\mathrm{pH}$, conductivity, DO, and SVI) alone explained $10.10 \%$ of the bacterial community variation (Figure 4). Nutrients (including nitrite, nitrate, TN, TP, and COD) alone explained $7.99 \%$ of the variation. Physicochemical factors and nutrients together explained $18.34 \%$ of the variation (Figure 4 ).

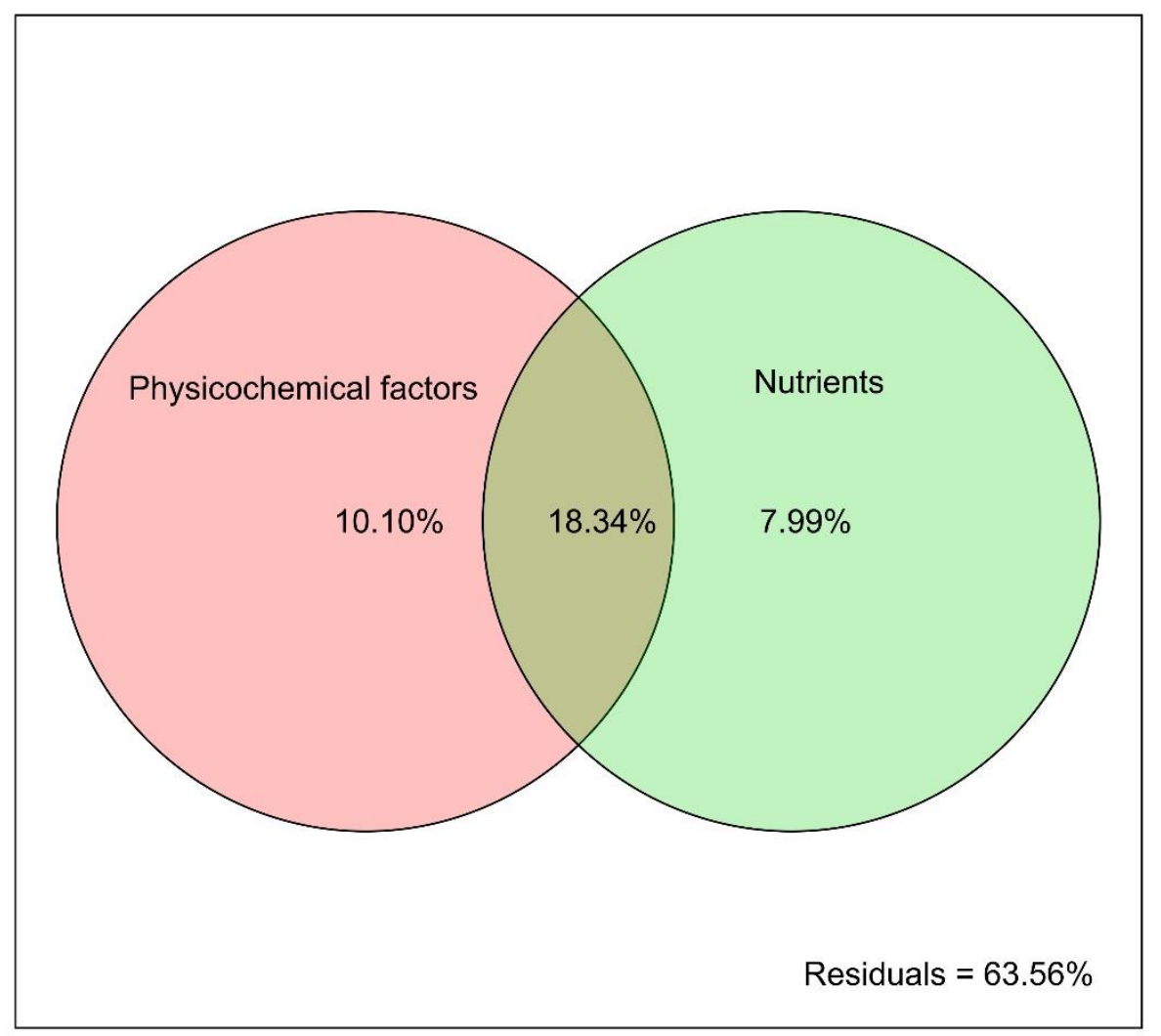

Figure 4. Venn diagram showing the contribution of environmental factors to community variation using variance partitioning analysis (VPA) analysis.

\subsection{Prediction of Microbial Community Function}

To study bacterial functions in different samples, functional prediction analysis was performed using the FAPROTAX software. The primary functional genes were chemoheterotrophy, aerobic chemoheterotrophy, fermentation, nitrification, aerobic nitrite oxidation, and animal parasites or symbionts (Figure 5).

In WWTP A, all functional genes were reduced from Stage 1 (BXAS 1) to Stage 3 (BXAS 5 and BXAS 6). For example, animal parasites or symbionts and human pathogens were reduced from $6.32 \%$ and $4.06 \%$ to $0.025 \%$ and $0.815 \%$. In Stage 2 (BXAS 2, BXAS 3, and BXAS 4$)$, the average proportion of nitrification $(4.51 \%)$ and aerobic nitrite oxidation (3.18\%) genes were higher than those in Stage $1(1.13 \%, 1.11 \%)$ and Stage $3(0.76 \%, 0.14 \%)$. In addition, the distribution of aerobic nitrite oxidation (BXAS 2 (1.54\%), BXAS $3(3.40 \%)$, and BXAS $4(4.60 \%))$ was the highest in BXBS $4(4.60 \%)$.

Similarly, from Stage 1 (BXBS 1) to Stage 3 (BXBS 5 and BXBS 6), all functional genes were reduced in WWTP $B$. The proportions of nitrification and aerobic nitrite oxidation functional genes were similar in all biological tanks. In Stage 2, aerobic chemoheterotrophy and fermentation were the major functional genes. However, the main functional genes of the primary clarifier of WWTP A (BXAS 1) and WWTP B (BXBS 1) were different, with aerobic chemoheterotrophy (5.93\%) and fermentation (10.84\%) being the highest in BXAS 1, while nitrification $(9.12 \%)$ and aerobic nitrite oxidation $(6.10 \%)$ were the highest in BXBS 1. 


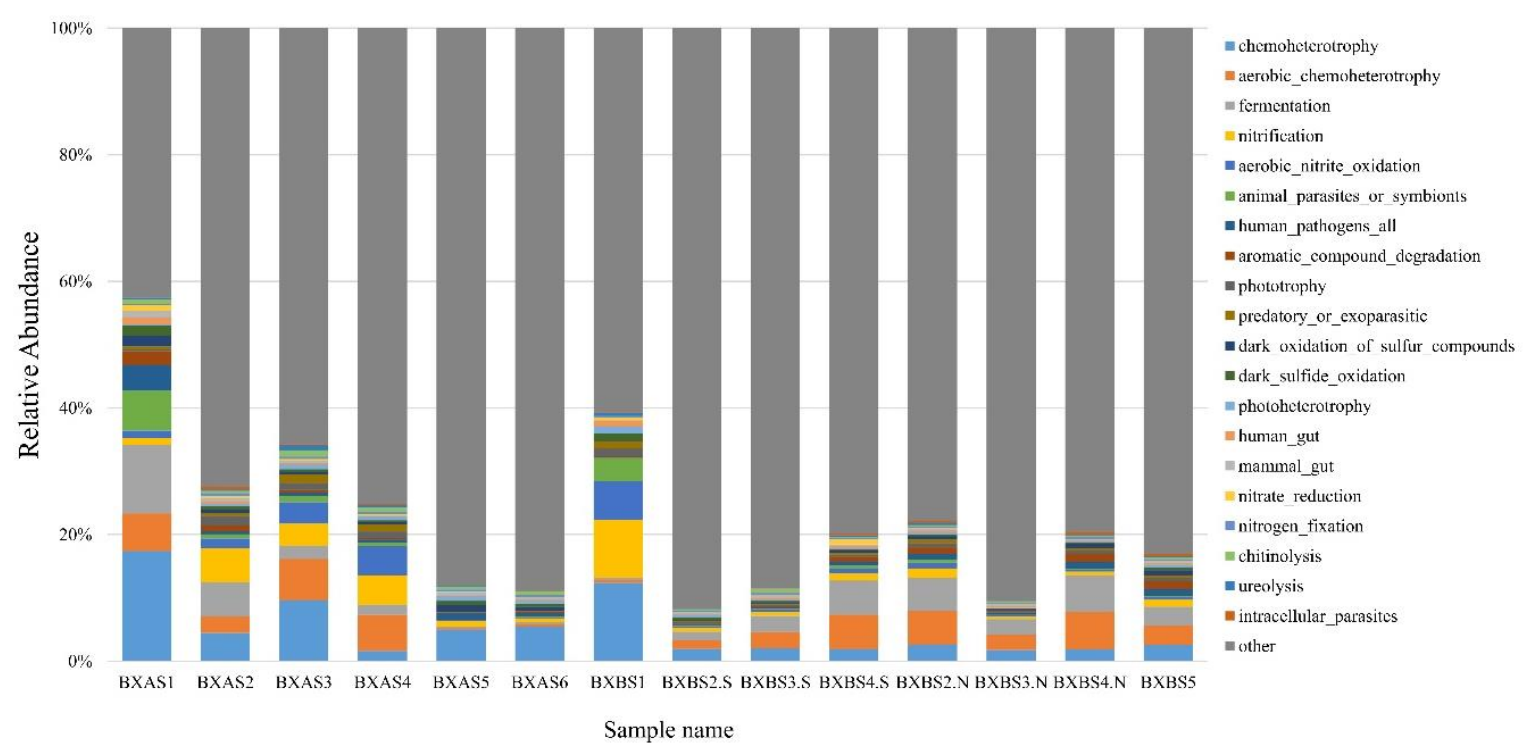

Figure 5. Bar chart of relative abundance of top 20 functions of the sample.

\section{Discussion}

The microbial composition of the AS of WWTPs is important for its treatment characteristics. In this study, the Chao1, observed species, and Shannon indices of sample BXBS 5 in WWTP B were the highest among all the samples, indicating that the species richness and diversity in the sludge storage tank was the highest (Table 1). The biological tanks in WWTP B consist of northern and southern parts. The sewage from two parts mixed in the sludge storage tank results in a relatively high species richness and diversity of sample BXBS 5. Nitrate, TN, COD, and nutrients were strong factors that influenced the microbial community compositions of these two projects.

Among the 14 samples collected in this study, Proteobacteria was the most abundant phylum, followed by Bacteroidetes, Acidobacteria, Firmicutes, and Nitrospirae. This is consistent with other studies, which have shown that the dominant microbial populations in most AS systems are Proteobacteria and Bacteroidetes [31-33]. Members of Proteobacteria have been reported to play a major role in WWTPs by removing organic pollutants and denitrification [34-36]. Members of Firmicutes contain a variety of aerobic and facultatively anaerobic bacteria, which can produce various enzymes that break down pollutants. Other studies have found Firmicutes to be the dominant phylum in WWTPs [8].

In WWTP A, AS flows through anaerobic, anoxic, and aerobic tanks, and then flows back to the biological tanks through sludge refluxing, forming a circular system. Therefore, the microbial composition of the anaerobic, anoxic, and aerobic tanks is very similar. However, the proportion of the bacteria changed in different tanks. This is consistent with the study of biological tanks in other WWTPs [8]. Nitrospirae members are usually the main nitrite-oxidizing bacteria (NOB) present in aerobic tanks of WWTPs [37,38], with the function of oxidizing nitrite to nitrate. In our study, the proportion of Nitrospirae was the highest in the aerobic tank of WWTP A (BXAS 2). Chloroflexi contributes to flocculation in AS and exists as flocculent skeletons inside sludge colloidal flocs [39]. It can degrade macromolecular organic matter [40] and remove phosphorus from sewage [41]. The highest proportion of Chloroflexi was also found in BXAS 2.

Haliangium, Arcobacter, Ferruginibacter, Cloacibacterium, and Nitrospira were the top five genera found. Arcobacter is considered a potential pathogen, and higher proportions were found in Stage 1 of both WWTP A and WWTP B (BXAS 1 and BXBS 1). After biological treatment, the proportion of Arcobacter was significantly reduced in Stage 3. This indicates that the WWTPs can play a positive role and reduce the level of potential pathogens in sewage. 
Understanding the potential functions of microorganisms in WWTPs is of great importance [32]. Yang et al. [42] studied the communities of a highly polluted river system and identified nine functional groups of the potential pathogens using FAPROTAX. In this study, FAPROTAX was used to predict the possible functions of the bacterial community. The results showed that the prominent functional gene families included nitrification, aerobic nitrite oxidation, human pathogens bacteria, and phototrophy. Moreover, they indicated high activity of the nitrogen-removal-related bacteria during the WWTP process. FAPROTAX function prediction helps to understand the potential functions in AS systems of WWTPs. Studies of microbial communities enriched our understanding of microbial communities in WWTPs. At the same time, it reveals the related species and changes between different tanks. These will help us improve the exact process that possibly affects the stability and efficiency of WWTPs.

\section{Conclusions}

There was no significant difference in community composition between WWTP A and WWTP B, but there was a substantial difference between Stage 1 and Stage 2. The essential factors affecting community structure and distribution were TN, COD, and nutrients. The community structure analysis of the phyla indicated that Proteobacteria, Bacteroidetes, Acidobacteria, Firmicutes, and Nitrospirae were the most dominant phyla in the samples. The dominant phylum in each sample was similar, but the proportion was different in each operating unit. Functional gene families of nitrification, aerobic nitrite oxidation, human pathogens bacteria, and phototrophy showed high abundance in the samples.

Author Contributions: Conceptualization, S.L. and H.C.; methodology, L.Z. and M.Z.; formal analysis, L.O. and H.C.; investigation, L.Z., Q.Z., L.O., K.W. and W.X.; writing-original draft preparation, L.Z.; writing-review and editing, M.Z., F.X. and L.O.; supervision, S.L. and N.X. All authors have read and agreed to the published version of the manuscript.

Funding: This study was supported by the National Key Research and Development Program of China(2020YFD0901003), Shenzhen science and technology application demonstration project (Grant No. KJYY20180201180253571), and Shenzhen Science and Technology Innovation ShenzhenHongKong Joint Research Project (SGLH20180622152010394).

Institutional Review Board Statement: Not applicable for studies not involving humans or animals.

Informed Consent Statement: Not applicable for studies not involving humans.

Data Availability Statement: The data presented in this study are available on request from the corresponding author.

Acknowledgments: We acknowledge the Health Time Gene for conducting the Illumina Novaseq Sequencing. We thank Instrument Analysis Center of Shenzhen University for the assistance with water quality parameter analysis

Conflicts of Interest: The authors declare no conflict of interest. The funders had no role in the design of the study; in the collection, analyses, or interpretation of data; in the writing of the manuscript, or in the decision to publish the results.

\section{References}

1. Wolff, S.; Weber, F.; Kerpen, J.; Winklhofer, M.; Engelhart, M.; Barkmann, L. Elimination of microplastics by downstream sand filters in wastewater treatment. Water 2021, 13, 33. [CrossRef]

2. Paliaga, P.; Felja, I.; Budisa, A.; Ivancic, I. The impact of a fish cannery wastewater discharge on the bacterial community structure and sanitary conditions of marine coastal sediments. Water 2019, 11, 2566. [CrossRef]

3. Islam, M.M.; Karim, M.R.; Zheng, X.; Li, X. Heavy metal and metalloid pollution of soil, water and foods in bangladesh: A critical review. Environ. Res. Public Health 2018, 15, 2825. [CrossRef]

4. Agoro, M.A.; Adeniji, A.O.; Adefisoye, M.A.; Okoh, O.O. Heavy metals in wastewater and sewage sludge from selected municipal treatment plants in eastern cape province, south Africa. Water 2020, 12, 2746. [CrossRef]

5. Wang, M.; Wu, Y.; Yang, B.; Deng, P.; Zhong, Y.; Fu, C.; Lu, Z.; Zhang, P.; Wang, J.; Qu, Y. Comparative study of the effect of rice husk-based powders used as physical conditioners on sludge dewatering. Sci. Rep. 2020, 10, 17230. [CrossRef] [PubMed] 
6. Zhang, T.; Shao, M.-F.; Ye, L. 454 Pyrosequencing reveals bacterial diversity of activated sludge from 14 sewage treatment plants. ISME J. 2012, 6, 1137-1147. [CrossRef] [PubMed]

7. Ju, F.; Zhang, T. Bacterial assembly and temporal dynamics in activated sludge of a full-scale municipal wastewater treatment plant. ISME J. 2015, 9, 683-695. [CrossRef] [PubMed]

8. Zhang, L.; Shen, Z.; Fang, W.; Gao, G. Composition of bacterial communities in municipal wastewater treatment plant. Sci. Total Environ. 2019, 689, 1181-1191. [CrossRef]

9. Nielsen, P.H.; Saunders, A.M.; Hansen, A.A.; Larsen, P.; Nielsen, J.L. Microbial communities involved in enhanced biological phosphorus removal from wastewater-a model system in environmental biotechnology. Curr. Opin. Biotechnol. 2012, 23, 452-459. [CrossRef]

10. Ju, F.; Guo, F.; Ye, L.; Xia, Y.; Zhang, T. Metagenomic analysis on seasonal microbial variations of activated sludge from a full-scale wastewater treatment plant over 4 years. Environ. Microbiol. Rep. 2014, 6, 80-89. [CrossRef]

11. Daims, H.; Taylor, M.W.; Wagner, M. Wastewater treatment: A model system for microbial ecology. Trends Biotechnol. 2006, 24, 483-489. [CrossRef]

12. Wan, W.; He, D.; Xue, Z. Removal of nitrogen and phosphorus by heterotrophic nitrification-aerobic denitrification of a denitrifying phosphorus-accumulating bacterium Enterobacter cloacae hw-15. Ecol. Eng. 2017, 99, 199-208. [CrossRef]

13. Zhang, M.; Pan, L.; Liu, L.; Su, C.; Dou, L.; Su, Z.; He, Z. Phosphorus and nitrogen removal by a novel phosphate-accumulating organism, Arthrobacter sp. Hhep5 capable of heterotrophic nitrification-aerobic denitrification: Safety assessment, removal characterization, mechanism exploration and wastewater treatment. Bioresour. Technol. 2020, 312, 123633. [CrossRef] [PubMed]

14. Schmid, M.; Thill, A.; Purkhold, U.; Walcher, M.; Bottero, J.Y.; Ginestet, P.; Nielsen, P.H.; Wuertz, S.; Wagner, M. Characterization of activated sludge flocs by confocal laser scanning microscopy and image analysis. Water Res. 2003, 37, 2043-2052. [CrossRef]

15. Guo, F.; Zhang, T. Profiling bulking and foaming bacteria in activated sludge by high throughput sequencing. Water Res. 2012, 46, 2772-2782. [CrossRef] [PubMed]

16. Sogin, M.L.; Morrison, H.G.; Huber, J.A.; Welch, D.M.; Huse, S.M.; Neal, P.R.; Arrieta, J.M.; Herndl, G.J. Microbial diversity in the deep sea and the underexplored "rare biosphere". Proc. Natl. Acad. Sci. USA 2006, 103, 12115-12120. [CrossRef] [PubMed]

17. Ye, L.; Zhang, T.; Wang, T.; Fang, Z. Microbial structures, functions, and metabolic pathways in wastewater treatment bioreactors revealed using high-throughput sequencing. Environ. Sci. Technol. 2012, 46, 13244-13252. [CrossRef]

18. Zhang, B.; Xu, X.; Zhu, L. Structure and function of the microbial consortia of activated sludge in typical municipal wastewater treatment plants in winter. Sci. Rep. 2017, 7, 17930. [CrossRef]

19. Cai, X.; Mao, Y.; Xu, J.; Tian, L.; Wang, Y.; Iqbal, W.; Yang, B.; Liu, C.; Zhao, X.; Wang, Y. Characterizing community dynamics and exploring bacterial assemblages in two activated sludge systems. Appl. Microbiol. Biotechnol. 2020, 104, 1795-1808. [CrossRef]

20. Chen, Y.; Li, S.; Lu, Y.; Zhu, G.; Cheng, H. Simultaneous nitrification, denitrification and phosphorus removal (SNDPR) at low atmosphere pressure. Biochem. Eng. J. 2020, 160, 107629. [CrossRef]

21. American Public Health Association. Standard Methods for the Examination of Water and Wastewater; APHA: Washington, DC, USA, 2007.

22. Liu, M.; Gill, J.J.; Young, R.; Summer, E.J. Bacteriophages of wastewater foaming-associated filamentous Gordonia reduce host levels in raw activated sludge. Sci. Rep. 2015, 5, 13754. [CrossRef]

23. Justin, K.; Jesse, S.; Anton, W.W.; Antonio, G.; Gregory, C.J.; Rob, K. Using QIIME to analyze 16s rRNA gene sequences from microbial communities. Curr. Protoc. 2012, 27, 1E.5.1-1E.5.20.

24. Magoc, T.; Salzberg, S.L. Flash: Fast length adjustment of short reads to improve genome assemblies. Bioinformatics 2011, 27, 2957-2963. [CrossRef] [PubMed]

25. Edgar, R.C.; Haas, B.J.; Clemente, J.C.; Quince, C.; Knight, R. UCHIME improves sensitivity and speed of chimera detection. Bioinformatics 2011, 27, 2194-2200. [CrossRef] [PubMed]

26. Rognes, T.; Flouri, T.; Nichols, B.; Quince, C.; Mahe, F. VSEARCH: A versatile open source tool for metagenomics. PeerJ 2016, 4, e2584. [CrossRef] [PubMed]

27. Schmidt, P.-A.; Balint, M.; Greshake, B.; Bandow, C.; Römbke, J.; Schmitt, I. Illumina metabarcoding of a soil fungal community. Soil Biol. Biochem. 2013, 65, 128-132. [CrossRef]

28. Somerfield, P.J. Identification of the Bray-Curtis similarity index: Comment on Yoshioka (2008). Mar. Ecol. Prog. Ser. 2008, 372, 303-306. [CrossRef]

29. Yoshioka, P.M. Misidentification of the Bray-Curtis similarity index. Mar. Ecol. Prog. Ser. 2008, 368, 309-310. [CrossRef]

30. Haller, L.; Tonolla, M.; Zopfi, J.; Peduzzi, R.; Wildi, W.; Pote, J. Composition of bacterial and archaeal communities in freshwater sediments with different contamination levels (Lake Geneva, Switzerland). Water Res. 2011, 45, 1213-1228. [CrossRef]

31. Gao, P.; Xu, W.; Sontag, P.; Li, X.; Xue, G.; Liu, T.; Sun, W. Correlating microbial community compositions with environmental factors in activated sludge from four full-scale municipal wastewater treatment plants in shanghai, China applied microbiology and biotechnology. Appl. Microbiol. Biotechnol. 2016, 100, 4663-4673. [CrossRef]

32. Xia, Y.; Wen, X.; Zhang, B.; Yang, Y. Diversity and assembly patterns of activated sludge microbial communities: A review. Biotechnol. Adv. 2018, 36, 1038-1047. [CrossRef]

33. Han, I.; Yoo, K. Metagenomic profiles of antibiotic resistance genes in activated sludge, dewatered sludge and bioaerosols. Water 2020, 12, 1516. [CrossRef] 
34. Chen, H.J.; Lin, Y.Z.; Fanjiang, J.M.; Fan, C. Microbial community and treatment ability investigation in AOAO process for the optoelectronic wastewater treatment using PCR-DGGE biotechnology. Biodegradation 2013, 24, 227-243. [CrossRef] [PubMed]

35. Cydzik-Kwiatkowska, A.; Zielinska, M. Bacterial communities in full-scale wastewater treatment systems. World J. Microbiol. Biotechnol 2016, 32, 66. [CrossRef] [PubMed]

36. Wang, Z.; Zhang, X.-X.; Lu, X.; Liu, B.; Li, Y.; Long, C.; Li, A. Abundance and diversity of bacterial nitrifiers and denitrifiers and their functional genes in tannery wastewater treatment plants revealed by high-throughput sequencing. PLoS ONE 2014, 9 e113603. [CrossRef]

37. Rodríguez, E.; García-Encina, P.A.; Stams, A.J.M.; Maphosa, F.; Sousa, D.Z. Meta-omics approaches to understand and improve wastewater treatment systems. Rev. Environ. Sci. Bio. Technol. 2015, 14, 385-406. [CrossRef]

38. Nielsen, P.H.; Mielczarek, A.T.; Kragelund, C.; Nielsen, J.L.; Saunders, A.M.; Kong, Y.; Hansen, A.A.; Vollertsen, J. A conceptual ecosystem model of microbial communities in enhanced biological phosphorus removal plants. Water Res. 2010, 44, 5070-5088. [CrossRef]

39. Larsen, P.; Nielsen, J.L.; Otzen, D.; Nielsen, P.H. Amyloid-like adhesins produced by floc-forming and filamentous bacteria in activated sludge. Appl. Environ. Microbiol. 2008, 74, 1517-1526. [CrossRef]

40. Bjornsson, L.; Hugenholtz, P.; Tyson, G.W.; Blackall, L.L. Filamentous chloroflexi (green non-sulfur bacteria) are abundant in wastewater treatment processes with biological nutrient removal. Microbiology 2002, 148, 2309-2318. [PubMed]

41. Kragelund, C.; Caterina, L.; Borger, A.; Thelen, K.; Eikelboom, D.; Tandoi, V.; Kong, Y.; Van Der Waarde, J.; Krooneman, J.; Rossetti, S.; et al. Identity, abundance and ecophysiology of filamentous chloroflexi species present in activated sludge treatment plants. Fems. Microbiol. Ecol. 2007, 59, 671-682. [CrossRef]

42. Yang, Y.; Hou, Y.; Ma, M.; Zhan, A. Potential pathogen communities in highly polluted river ecosystems: Geographical distribution and environmental influence. Ambio 2020, 49, 197-207. [CrossRef] [PubMed] 